Article

\title{
The Late-Stage Protective Effect of Mito-TEMPO against Acetaminophen-Induced Hepatotoxicity in Mouse and Three-Dimensional Cell Culture Models
}

\author{
Mohammad Abdullah-Al-Shoeb ${ }^{1,2,3,+} \oplus$, Kenta Sasaki ${ }^{1,+}{ }^{+}$, Saori Kikutani ${ }^{1}$, Nanami Namba ${ }^{1}$, \\ Keiichi Ueno ${ }^{1}$, Yuki Kondo ${ }^{1}{ }^{\circledR}$, Hitoshi Maeda ${ }^{4}$, Toru Maruyama ${ }^{4}$, Tetsumi Irie ${ }^{1,2}$ and \\ Yoichi Ishitsuka $1, *$ (D) \\ 1 Department of Clinical Chemistry and Informatics, Graduate School of Pharmaceutical Sciences, \\ Kumamoto University, 5-1 Oe-honmachi, Chuo-ku, Kumamoto 862-0973, Japan; \\ shoebbmb@gmail.com (M.A.-A.-S.); dstcomrelat119@gmail.com (K.S.); \\ 141p1014@st.kumamoto-u.ac.jp (S.K.); 140p1032@st.kumamoto-u.ac.jp (N.N.); \\ 157p1004@st.kumamoto-u.ac.jp (K.U.); ykondo@kumamoto-u.ac.jp (Y.K.); tirie@gpo.kumamoto-u.ac.jp (T.I.) \\ 2 Program for Leading Graduate Schools "HIGO (Health Life Science: Interdisciplinary and Glocal Oriented) \\ Program", Kumamoto University, 5-1 Oe-honmachi, Chuo-ku, Kumamoto 862-0973, Japan \\ 3 Department of Biochemistry and Molecular Biology, School of Life Sciences, \\ Shahjalal University of Science and Technology, Sylhet 3114, Bangladesh \\ 4 Department of Biopharmaceutics, Graduate School of Pharmaceutical Sciences, Kumamoto University, \\ 5-1 Oe-honmachi, Chuo-ku, Kumamoto 862-0973, Japan; maeda-h@kumamoto-u.ac.jp (H.M.); \\ tomaru@gpo.kumamoto-u.ac.jp (T.M.) \\ * Correspondence: y-zuka@gpo.kumamoto-u.ac.jp; Tel.: +81-96-371-4559 \\ + These authors contributed equally to this work.
}

Received: 18 September 2020; Accepted: 6 October 2020; Published: 9 October 2020 updates

\begin{abstract}
An overdose of acetaminophen (APAP), the most common cause of acute liver injury, induces oxidative stress that subsequently causes mitochondrial impairment and hepatic necroptosis. $\mathrm{N}$-acetyl-L-cysteine (NAC), the only recognized drug against APAP hepatotoxicity, is less effective the later it is administered. This study evaluated the protective effect of mitochondria-specific Mito-TEMPO (Mito-T) on APAP-induced acute liver injury in C57BL/6J male mice, and a three dimensional (3D)-cell culture model containing the human hepatoblastoma cell line HepG2. The administration of Mito-T ( $20 \mathrm{mg} / \mathrm{kg}$, i.p.) $1 \mathrm{~h}$ after APAP ( $400 \mathrm{mg} / \mathrm{kg}$, i.p.) injection markedly attenuated the APAP-induced elevated serum transaminase activity and hepatic necrosis. However, Mito-T treatment did not affect key factors in the development of APAP liver injury including the activation of c-jun N-terminal kinases (JNK), and expression of the transcription factor C/EBP homologous protein (CHOP) in the liver. However, Mito-T significantly reduced the APAP-induced increase in the hepatic oxidative stress marker, nitrotyrosine, and DNA fragmentation. Mito-T markedly attenuated cytotoxicity induced by APAP in the HepG2 3D-cell culture model. Moreover, liver regeneration after APAP hepatotoxicity was not affected by Mito-T, demonstrated by no changes in proliferating cell nuclear antigen formation. Therefore, Mito-T was hepatoprotective at the late-stage of APAP overdose in mice.
\end{abstract}

Keywords: liver injury; acetaminophen; Mito-TEMPO; mitochondria; CCAAT/enhancer binding protein homologous protein; c-jun N-terminal kinases; endoplasmic reticulum; ER stress

\section{Introduction}

Acetaminophen (N-acetyl-p-amino phenol; Paracetamol; APAP) is an over-the-counter drug, mostly used as an analgesic and antipyretic for different age groups worldwide with some after-effects 
at therapeutic doses [1,2]. However, an accidental or intentional overdose of APAP can cause acute hepatotoxicity that progresses to acute liver failure (ALF) [3]. APAP hepatotoxicity is responsible for about $46 \%$ of all ALF cases in the United States, and 40 to $70 \%$ in the United Kingdom and Europe [4-7]. Hepatic CYP2E1 (cytochrome P450) converts absorbed APAP into a very unstable toxic compound $\mathrm{N}$-acetyl-p-benzoquinoneimine (NAPQI), a glutathione (GSH) conjugate $[8,9]$. Following an overdose of APAP, hepatic GSH becomes depleted and the NAPQI concentration increases. The excessively unstable toxic metabolite NAPQI can bind to sulfhydryl groups of cellular and mitochondrial proteins (for example, glutathione peroxidases, ATP synthase $\alpha$-subunit) $[10,11]$. Mitochondrial protein-NAPQI adducts induced mitochondrial oxidative stress by impairing mitochondrial respiration [12] and cellular protein-NAPQI adducts activated JNK, which amplified mitochondrial protein-NAPQI-induced reactive oxygen species (ROS) generation $[13,14]$. Although the mechanism of mitochondrial oxidative stress in APAP-induced liver injury is poorly understood, mitochondrial oxidative stress is probably caused by electrons leaking from the electron transport chain (ETC) $[15,16]$. Moreover, the progression of hepatic injury involves multiple mediators including ROS, activated c-jun N-terminal kinase (JNK), C/EBP homologous protein (CHOP) induction, peroxynitrite, nitrotyrosine formation, and inflammatory mediators including interleukins (IL) and TNF- $\alpha$ [15,17-22].

Mitochondria are abundant in cellular systems and play a pivotal role by regulating energy metabolism, the cell cycle, ROS generation, and calcium homeostasis [23,24], and the mitochondrial activity and homeostasis of the redox state are crucial for controlling cellular survival and cell death pathways. Mitochondrial disorders generated by the metabolism of molecular oxygen and changes in the redox homeostatic nexus cause mitochondrial dysfunction [25]. Because mitochondrial dysfunction contributes to different common pathologies, mitochondria-targeted drug delivery is becoming an attractive mode of therapy [26]. Furthermore, mitochondrial oxidative stress-mediated mitochondrial dysfunction has a critical role in the development of APAP-induced acute liver injury and acute liver failure [27]. Therefore, drugs that have pleiotropic effects on mitochondria were identified as therapeutic agents against APAP-induced liver injury [28,29]. Moreover, mitochondria restoration or exogenous mitochondria might be an alternative treatment [30]. However, no mitochondria-specific antioxidant has been authorized for the attenuation of mitochondrial oxidative stress [25]. Mito-TEMPO (Mito-T) is a mitochondria-specific antioxidant [31] that has significant protective effects against APAP-induced acute liver injury [32,33].

In this study, we confirmed the protective effect of Mito-T against APAP-induced acute liver injury in mouse and human models. Mito-T contains a hydrophobic tetramethylpiperidine (TEMPO) group and lipophilic triphenyl phosphonium cation $\left(\mathrm{TPP}^{+}\right)$that are responsible for incorporation into mitochondria and scavenging mitochondrial superoxides, respectively [31]. The purpose of this study was to confirm the effectiveness of Mito-T against acute liver injury induced by an overdose of APAP, and the protective effect of Mito-T against APAP-induced mitochondrial oxidative stress, nitrotyrosine formation, and hepatic necroptosis in mice. We also observed the effect of Mito-T on liver regeneration after acute liver injury in mice. In addition, the effects of Mito-T against APAP-induced hepatocellular injury and mitochondrial oxidative stress were evaluated in a human HepG2 three-dimensional cell culture model.

\section{Materials and Methods}

\subsection{Experimental Materials}

Mito-TEMPO (Mito-T), acetaminophen (APAP), N-acetyl-L-cysteine (NAC), SP600125-JNK inhibitor, and Solution HS-15 were procured from Sigma-Aldrich Corporation (St. Louis, MO, USA). Concanavalin A (ConA), carbon tetrachloride $\left(\mathrm{CCl}_{4}\right)$, corn oil, $10 \%$ formalin neutral buffer solution, and dehydrated dimethyl sulfoxide (DMSO) were procured from Wako Pure Chemical Industries, Ltd. (Osaka, Japan). Dulbecco's modified Eagle's medium containing a low glucose concentration (DMEM), penicillin/streptomycin (Pen Strep), and 2.5\% trypsin (10×) was purchased from Gibco ${ }^{\circledR}$ 
Life Technologies (Life Technologies Japan, Tokyo, Japan). Fetal bovine serum (FBS) was purchased from Biowest (Nuaillé, France). A cell counting kit (WST8) was obtained from Dojindo Laboratories (Kumamoto, Japan). MitoSOX ${ }^{\mathrm{TM}}$ Red mitochondrial superoxide indicator was purchased from Invitrogen (Thermo Fisher Scientific, Waltham, MA, USA). NanoCulture Plate MH pattern Low-binding 96 well Ver. 2 (Code No. NG-PLH9010) was purchased from MBL International Corporation ${ }^{\circledR}$ (Woburn, MA, USA). All additional reagents and solvents utilized in this study were of reagent grade. Distilled and de-ionized bio-pure grade water was used in this study.

\subsection{Animals and Protocols}

We used the previously reported APAP-induced hepatic injury model in this study [34-36]. For in vivo experiments, 7-8-week-old male wild type C57BL/6J Jcl mice (CLEA Japan Inc., Tokyo, Japan) were used. The APAP and ConA-induced liver injury mouse models were prepared by dissolving APAP $(400 \mathrm{mg} / \mathrm{kg})$, and ConA $(12.5 \mathrm{mg} / \mathrm{kg})$ in phosphate buffered saline (PBS) to give a dose of $1 \mathrm{~mL}$ and $0.625 \mathrm{~mL}$ per $50 \mathrm{~g}$ body weight of C57BL/6J mouse, respectively. Dissolved APAP was heated to about $60^{\circ} \mathrm{C}$ and cooled to $40-50^{\circ} \mathrm{C}$ before intraperitoneal administration, whereas the ConA solution was administered intravenously. The $\mathrm{CCl}_{4}$ induced liver injury mouse model was prepared by dissolving $\mathrm{CCl}_{4}(0.025 \mathrm{~mL} / \mathrm{kg})$ in corn oil to a dose of $0.5 \mathrm{~mL}$ per $50 \mathrm{~g}$ of C57BL/6J mouse body weight and then administered intraperitoneally. All experimental animals were kept under controlled conditions (12-h light/dark cycle at $24^{\circ} \mathrm{C}$ ) with free access to food and water. We followed the guidelines of the Committee for Ethics on Animal Experiments of Kumamoto University (Approval numbers A27-131, A29-132, and A2019-102) for all our animal experiments and animal handling.

\subsection{Drug Administration}

Mito-T (2-20 mg/kg) was suspended in saline and injected intraperitoneally into mice at a dose of $0.5 \mathrm{~mL}$ per $50 \mathrm{~g}$ of mouse body weight. NAC $(600 \mathrm{mg} / \mathrm{kg})$ was suspended in saline to a dose of $0.6 \mathrm{~mL}$ per $50 \mathrm{~g}$ of mouse body weight and administered intraperitoneally.

\subsection{Measurement of Alanine Aminotransaminase (ALT) Activity}

Mice were anesthetized by the inhalation of isoflurane (Wako Pure Chemical Industries Ltd., Osaka, Japan) and then euthanized during sample collection. After laparotomy with a scalpel, a $1 \mathrm{~mL}$ syringe and $26 \mathrm{G} \times 1 / 2^{\prime \prime}(0.45 \times 13 \mathrm{~mm})$ injection needle (Terumo ${ }^{\circledR}$ Corporation, Tokyo, Japan) were used to collect blood from the abdominal vena cava. Whole blood samples were kept for 30-50 min at room temperature, and then centrifuged $\left(3000 \times \mathrm{g}, 10 \mathrm{~min}, 4^{\circ} \mathrm{C}\right)$. Then, the supernatant of serum samples was collected and serum ALT levels were determined according to the supplier's guidelines using a commercially available SPOTCHEM ${ }^{\mathrm{TM}}$ IIGPT/ALT assay kit (REF 77170) and automated clinical analyzer SPOTCHEM ${ }^{\mathrm{TM}}$ EZ SP-4430 (ARKRAY, Inc., Kyoto, Japan) [34].

\subsection{Hepatic Histopathology}

Liver histopathology was performed according to a previously described protocol [34]. In brief, histopathological specimens were prepared by fixing livers isolated from mice with $10 \%$ formalin neutral buffer solution followed by paraffin embedding using common methods. We cut $3-\mu \mathrm{m}$ thick microtome sections and hematoxylin-eosin (H\&E) staining was performed to observe necrotic cell death in APAP overdose livers. Terminal deoxynucleotidyl transferase-mediated dUTP nick end labeling (TUNEL) staining of liver samples was performed to observe hepatocyte death using an ApopTag ${ }^{\circledR}$ Peroxidase In Situ Apoptosis Detection Kit (Merck Millipore, Billerica, MA, USA) according to the protocol supplied by the manufacturer. Images of stained sections were captured by a KEYENCE BIOREVO BZ-9000 microscope (Keyence Corporation, Osaka, Japan). 


\subsection{Immunostaining}

For immunostaining, liver tissue samples were prepared, and immunohistochemistry was performed as previously reported [36]. Histopathological specimens were prepared by fixing livers isolated from mice with $4 \%$ paraformaldehyde and then embedding them in paraffin. We cut 3- $\mu \mathrm{m}$ thick microtome sections and immunostained them with three different antibodies (CHOP antibody, nitrotyrosine antibody, and PCNA antibody). Images of the stained liver samples were captured using the KEYENCE BIOREVO BZ-9000 microscope. We took 10 randomly-chosen images from each liver sample and counted the number of positive cells in each image (Supplemental Figure S1). The number of CHOP positive cells is shown as the mean of 10 fields.

\subsection{Hepatic Total Glutathione Content}

Liver specimens were prepared and the total glutathione (tGSH) level was estimated by the previously demonstrated technique [36,37]. Briefly, liver tissue samples were weighed after collection and stored $\left(-80{ }^{\circ} \mathrm{C}\right)$ until tGSH was estimated. Then, tissue homogenates were suspended in $5 \mathrm{~mL}$ of $5 \%$ metaphosphoric acid solution at a ratio of $1: 5(w / v)$ and centrifuged for $15 \mathrm{~min}$ at $8000 \times g$ at $4{ }^{\circ} \mathrm{C}$. The supernatant was collected and the tGSH concentration was determined by BIOXYTECH GSH/GSSG-412 (OXIS Health Products, Inc, Portland, OR, USA). Absorbance was measured using a spectrophotometer (V-530, JASCO Corporation, Tokyo, Japan) and the total GSH content was expressed as $\mathrm{nmol} / \mathrm{mg}$ tissue.

\subsection{Western Blotting}

Protein expression was estimated by western blotting as previously reported [34,36]. In brief, $4 \mathrm{~h}$ after the administration of APAP, liver samples were excised, balanced to $150 \mathrm{mg}$, and kept in $0.5 \mathrm{~mL}$ of RIPA mix $(490 \mu \mathrm{L}$ of radio-immunoprecipitation assay (RIPA) buffer (Wako Pure Chemical Industries Ltd.), $5 \mu \mathrm{L}$ of Halt ${ }^{\mathrm{TM}}$ protease inhibitor cocktail (Thermo Fisher Scientific) and $5 \mu \mathrm{L}$ of Halt ${ }^{\mathrm{TM}}$ phosphatase inhibitor cocktail (Thermo Fisher Scientific)). Liver samples were homogenized using Micro Smash ${ }^{\mathrm{TM}}$ MS-100R (TOMY MEDICO., LTD, Tokyo, Japan) at 4000 rpm using zirconia and stainless-steel beads, and the supernatant was collected for quantitative BCA protein measurement as well as a protein extract solution. The protein samples were subjected to separation by SDS-polyacrylamide gel electrophoresis (SDS-PAGE) using 0.5 M/1.5 M Tris- $\mathrm{HCl}, 40 \%$ acrylamide, 10\% sodium dodecyl sulfate, tetramethylethylenediamine (Sigma-Aldrich) and 0.1\% Tris Buffered Saline (TBS-T). After separation, proteins from the gel were transferred onto a polyvinylidene difluoride (PVDF) membrane (Millipore Corp., Burlington, MA, USA) by Transblot (Bio-Rad Laboratories Inc., Berkeley, CA, USA). After blocking the membranes with 5\% skim milk, they were washed three times with TBS in Tween-20, and incubated overnight in diluted primary antibody at $4{ }^{\circ} \mathrm{C}$. Primary antibodies specific for CYP2E1 (Abcam Inc., Cambridge, MA, USA), $p$-JNK, JNK, and $\beta$-actin (Cell Signaling Technology, Danvers, MA, USA) were diluted at 1:1000. The PVDF membrane was rinsed three times with TBS in Tween-20 and stained with complementary secondary antibodies conjugated to anti-rabbit IgG (Cell Signaling Technology) (1:3000). To detect the antibody staining, SuperSignal ${ }^{\circledR}$ West Pico Chemiluminescent Substrate (Thermo Scientific) was used, and the emission signal was visualized using Image Quant LAS-4000 (GE Healthcare Japan Corporation, Tokyo, Japan).

\subsection{Hepatic $m R N A$ Isolation and Real-Time RT-PCR}

The liver specimens were balanced, chilled, and kept in RNAlater ${ }^{\mathrm{TM}}$ solution (Invitrogen, Thermo Fisher Scientific) until assayed [35,37]. To isolate mRNA from the hepatic tissue samples, the liver tissues were homogenized using Micro Smash ${ }^{\mathrm{TM}}$ MS-100R (Tomy Medico Ltd.) in TRIzol ${ }^{\circledR}$ reagent (Invitrogen ${ }^{\mathrm{TM}}$-Life Technologies, Tokyo, Japan), zirconia, and stainless-steel beads according to the guidelines provided by the supplier. The RNA concentration of each sample was determined using an Eppendorf BioSpectrometer ${ }^{\circledR}$ kinetic (Eppendorf AG, Hamburg, Germany) and the samples 
were diluted to 200-2000 nM using RNase free water. cDNA libraries were prepared from the extracted hepatic RNA samples by using a High Capacity cDNA Reverse Transcription Kit (Applied Biosystems-Life Technologies, Tokyo, Japan). Quantitative real-time RT-PCR for mouse CHOP protein (Chop; NM_007837) and $\beta$-actin (NM_007393) was carried out using the following primers: CHOP forward, AGCTGGAAGCCTGGTATGAGGA, and reverse, AGCTAGGGACGCAGGGTCAA; $\beta$-actin forward, CATCCGTAAAGACCTCTATGCCAAC and reverse, ATGGAGCCACCGATCCACA. Real-time PCR analysis used diluted cDNA samples and Fast SYBR ${ }^{\circledR}$ Green master mix (Applied Biosystems-Life Technologies Japan). The $\Delta \Delta C t$ method of StepOne ${ }^{\mathrm{TM}}$ Real-Time PCR System (Applied Biosystems-Life Technologies Japan) was used. A melting curve was generated to determine specificity. The correlative magnitude of the target gene mRNA was determined as fold induction normalized to the $\beta$-actin level (endogenous control).

\subsection{Cell Cultures and Induction of the APAP Hepatotoxicity Model in 3-Dimensional HepG2 Cells}

The cell culture and in vitro studies were performed according to our previous report [35]. Briefly, HepG2 (RIKEN BioResource Center, Tokyo, Japan), a human hepatoblastoma cell line, was cultivated at $37^{\circ} \mathrm{C}$, under $95 \%$ air and $5 \% \mathrm{CO}_{2}$, in DMEM medium containing $10 \% \mathrm{FBS}, 100 \mathrm{U} / \mathrm{mL}$ penicillin, and $100 \mathrm{U} / \mathrm{mL}$ streptomycin in a SANYO CO ${ }_{2}$ incubator (Marshall Scientific, Hampton, NH, USA). For sub-culture and seeding in NCPs, the confluent culture was rinsed with PBS (pH 7.4), disassembled with $0.25 \%$ trypsin, and centrifuged to collect the cells. For the 3D-cell culture, 96 -well NCPs were used, and the cells were seeded at a density of $1 \times 10^{4}$ cells/well in $100 \mu \mathrm{L}$. To prepare the 3D-cell culture model, $50 \mu \mathrm{L}$ of DMEM medium was added to each well in 96-well NCPs and incubated for $10 \mathrm{~min}$. Then, a cell suspension at twice the desired concentration was prepared and $50 \mu \mathrm{L}$ of the cell suspension was added to the plate.

\subsection{Cell Viability Assays in the 3D-HepG2 Cell Model}

To evaluate APAP-induced cytotoxicity, we measured mitochondrial dehydrogenase activity in the 3D NCP-HepG2 cell culture using the WST-8 assay and Cell Counting Kit (Dojindo Laboratories) according to the supplier's method. HepG2 cells were seeded at a concentration of $1 \times 10^{4}$ cells/well in 96-well NCPs for 5 days. After spheroid formation, the cells were treated with $15 \mathrm{mM}$ APAP, $15 \mathrm{mM}$ APAP $+10 \mu \mathrm{M}$ of Mito-T, and $15 \mathrm{mM}$ of APAP $+100 \mu \mathrm{M}$ of NAC, for $48 \mathrm{~h}$ at $37^{\circ} \mathrm{C}$ in $5 \% \mathrm{CO}_{2}$. The reagents were dissolved in DMEM and the control group was treated with medium only. Then the cells were incubated with $10 \mu \mathrm{L}$ of WST- 8 reagents for $180 \mathrm{~min}$. WST- 8 treated samples were transferred to a 96-well cell-culture plate (Greiner Bio-One) and samples were measured at an absorbance of $450 \mathrm{~nm}$ using a microplate reader (Tecan Co., Ltd., Männedorf, Switzerland). The protective effect of Mito-T and NAC were measured by combination treatment on APAP-treated HepG2 cells. The percentage of cell viability was estimated compared with the untreated controls.

\subsection{Measurement of Mitochondrial Oxidative Stress in the 3D-HepG2 Cell Model}

Mitochondrial oxidative stress was evaluated using a Mito-SOX ${ }^{\mathrm{TM}}$ Red mitochondrial superoxide indicator (Thermo Fisher Scientific). HepG2 cells were cultivated in 96-well NCPs at $3.0 \times 10^{4}$ cells/well until spheroid formation and the spheroids were observed approximately within $72 \mathrm{~h}$. Then, the 3D-HepG2 cells were treated by the following conditions: Control group (medium only), APAP group (15 mM of APAP), APAP + Mito-T group (15 mM of APAP + $10 \mu \mathrm{M}$ of Mito-T), and APAP + NAC group (15 mM of APAP $+100 \mu \mathrm{M}$ of NAC). The reagents were dissolved in DMEM and the control group was treated with medium only. After $24 \mathrm{~h}$ exposure to the reagents, the cells were treated with $5 \mu \mathrm{M}$ of MitoSOX in DMEM for $15 \mathrm{~min}$ in the dark condition. Then, the medium containing MitoSOX was removed and replaced with PBS containing 5\% FBS. The cells were immediately imaged at excitation/emission wavelengths of 490/510 $\mathrm{nm}$ and under bright field using a microscope (BIOREVO BZ-9000; Keyence Co., Osaka, Japan). Random fields of each well were analyzed by microscopy and the quantification of 
MitoSOX fluorescence was performed using ImageJ software $(1.47 \mathrm{v}$, National Institutes of Health, Bethesda, MD, USA). The data were expressed as fluorescence intensity per field of cell occupied area.

\subsection{Statistical Analysis}

All the experimental data are the mean \pm standard error. Statistical analyses were performed using GraphPad Prism ver. 5.01 (GraphPad Software, San Diego, CA, USA). For comparisons between two groups, the F-test was used to test the population's equal variance. The Student's $t$-test was performed for equal variance and Welch's $t$-test was used for unequal variance. Non-parametric multiple comparisons were performed if the variance was not uniform and Kruskal-Wallis analysis was performed after confirming significant differences $(p<0.05)$. Comparisons among three or more groups were made by the multiple comparison test. Statistical significance among different groups was analyzed by one-way analysis of variance (ANOVA) after the identification of uniform variance by Bartlett's analysis $(p<0.05)$. When significant differences $(p<0.05)$ were observed, the data were analyzed further by Tukey's (or Tukey-Kramer) multiple range test as appropriate. For the therapeutic time window experiment data, two-way ANOVA was performed. When significant differences $(p<0.05)$ were identified, data were analyzed further using the Bonferroni method.

\section{Results}

\subsection{Protective Effect of Mito-T against APAP-Induced Liver Injury in C57BL/6J Mice}

A protective effect of Mito-T on liver injury was observed following an overdose of APAP in C57BL/6J Jcl wild type male mice. To confirm a dose dependent effect, four different doses of Mito-T (2, 5, 10, and $20 \mathrm{mg} / \mathrm{kg}$ ) were administered intraperitoneally $1 \mathrm{~h}$ after a single APAP injection (400 mg/kg, i.p.). The hepatic injury biomarker transaminase level (ALT) in serum was measured $24 \mathrm{~h}$ after APAP treatment. We found that $5-20 \mathrm{mg} / \mathrm{kg}$ Mito-T significantly $(p<0.01)$ suppressed the APAP-induced increase in serum ALT levels whereas $2 \mathrm{mg} / \mathrm{kg}$ of Mito-T had no protective effect (Figure 1A). This indicated the effective dose of Mito-T was $>5 \mathrm{mg} / \mathrm{kg}$, and $20 \mathrm{mg} / \mathrm{kg}$ of Mito-T was chosen for further experiments.

To observe the effect of Mito-T on APAP-treated mice, a time-course study of serum ALT activity was performed using eight groups containing 3-9 C57BL/6J mice per group. All eight groups were treated with $400 \mathrm{mg} / \mathrm{kg}$ APAP intraperitoneally, and then four groups were treated with Mito-T $(20 \mathrm{mg} / \mathrm{kg})$ and the other four groups were treated with saline $(20 \mathrm{mg} / \mathrm{kg}) 1 \mathrm{~h}$ after APAP administration. The serum ALT activity was measured at 4, 8, 24 and $48 \mathrm{~h}$ after APAP injection. The ALT kinetic data showed that after APAP exposure, the ALT activity started to increase at $4 \mathrm{~h}$ and peaked at $24 \mathrm{~h}$. Then, ALT activity declined to normal levels within $48 \mathrm{~h}$. However, after Mito-T administration, the ALT level was increased slightly at $8 \mathrm{~h}$ and remained at a normal level at the other time points (Figure 1B). Representative H\&E stained images showed the effect of APAP overdose ( $400 \mathrm{mg} / \mathrm{kg}$, i.p.) on mouse liver was time dependent. The histological images of APAP-treated mouse livers indicated zonal necroptosis, also termed centrilobular necroptosis around the central hepatic vein after $24 \mathrm{~h}$. Drug metabolizing enzymes were ubiquitously observed in the centrilobular area. In the Mito-T $(20 \mathrm{mg} / \mathrm{kg}$, i.p.) treated group, the H\&E staining showed an alleviation of the effect of APAP (Figure 1C). 
(A)

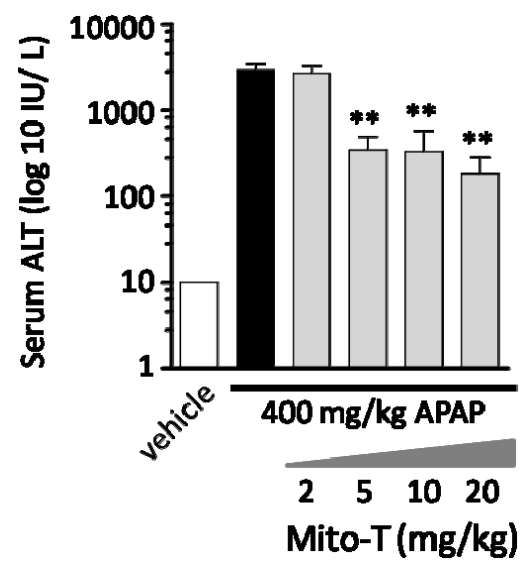

(B)

APAP $(400 \mathrm{mg} / \mathrm{kg}) \square$ APAP+Mito-T $(20 \mathrm{mg} / \mathrm{kg})$

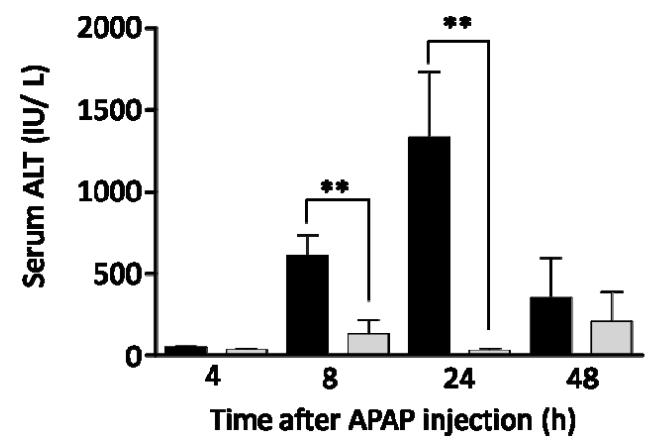

(C)

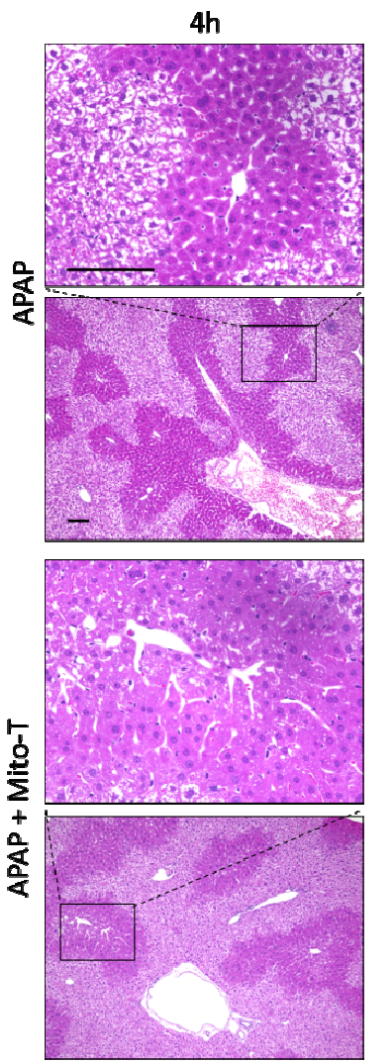

$8 \mathrm{~h}$
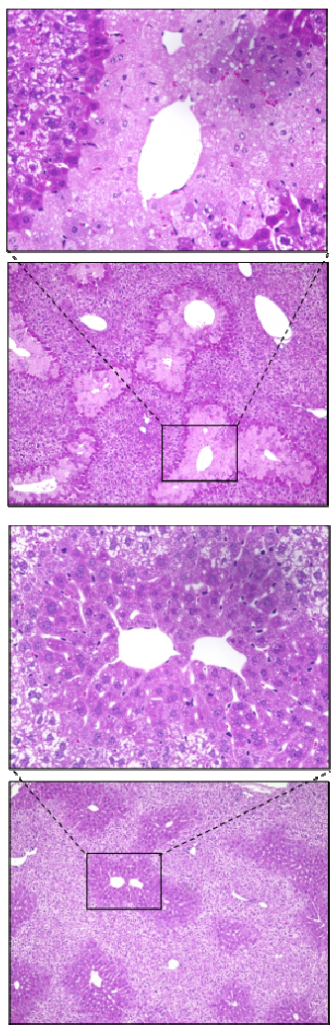

$24 \mathrm{~h}$
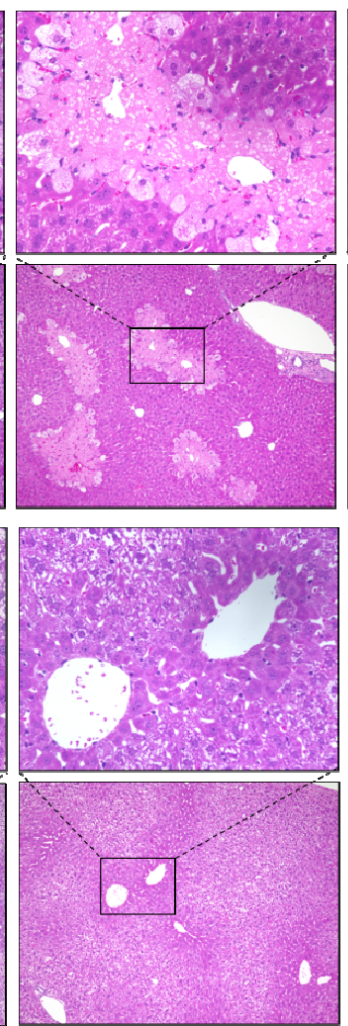

$48 \mathrm{~h}$
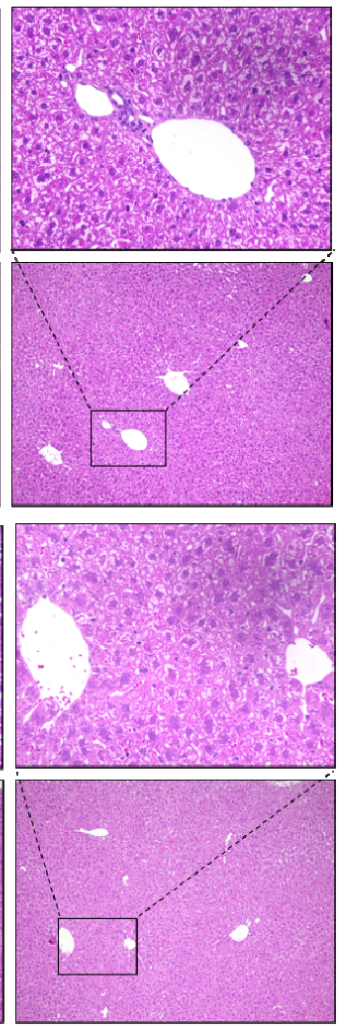

Figure 1. Mito-TEMPO (Mito-T) is hepatoprotective against acetaminophen (APAP) liver injury. (A) Mice were treated with $400 \mathrm{mg} / \mathrm{kg}$ APAP intraperitoneally, and then 2, 5, 10, or $20 \mathrm{mg} / \mathrm{kg} \mathrm{MT}$ or saline was administered intraperitoneally $1 \mathrm{~h}$ later. The serum ALT activity was measured $24 \mathrm{~h}$ after APAP injection. Each bar represents the mean \pm SEM of $3-5$ mice. ${ }^{* *} p<0.01$ vs. the APAP group. (B) Serum alanine aminotransaminase (ALT) activity was measured at 4, 8, 24, and $48 \mathrm{~h}$ after APAP ( $400 \mathrm{mg} / \mathrm{kg}$, i.p.) injection. Mito-T $(20 \mathrm{mg} / \mathrm{kg}$, i.p.) and saline were administered $1 \mathrm{~h}$ after APAP administration. Each bar represents the mean \pm SEM of $4-7$ mice. ${ }^{* *} p<0.01$ vs. the APAP group. (C) Representative hepatic sections from the APAP and APAP + Mito-T groups stained with H\&E at 4, 8, 24, and $48 \mathrm{~h}$ after APAP administration. 


\subsection{Efficacy of Mito-T on Liver Injury Progression in C57BL/6J Mice Following APAP Overdose}

APAP is metabolized to a cytotoxic compound NAPQI by the major drug-metabolizing enzyme CYP2E1. Then, NAPQI induces centrilobular hepatic damage and a reduction in the total glutathione (tGSH) level. In this study, we investigated whether there was any effect of Mito-T on the APAP metabolizing enzyme CYP2E1 and total GSH level in C57BL/6J mice. Mito-T (20 mg/kg, i.p.) was injected $1 \mathrm{~h}$ after APAP administration and samples were collected $4 \mathrm{~h}$ after APAP treatment. Whole liver western blotting showed that Mito-T did not affect CYP2E1 expression in the APAP-induced liver injury model (Figure 2A). Regarding the total glutathione level, a significant decrease was observed after the administration of APAP compared with the vehicle group; however, the decreased total glutathione amount was not alleviated by treatment with Mito-T (Figure 2B).

Activation of JNK in the hepatic cytosol is an early consequence of APAP-induced mitochondrial oxidative or nitrosative stress. Therefore, the effect of Mito-T on the expression of $p$-JNK was observed during APAP-induced liver injury progression. Mito-T (20 mg/kg, i.p.) was administered $1 \mathrm{~h}$ after APAP injection (400 mg/kg, i.p.) and liver tissue samples were collected $4 \mathrm{~h}$ after APAP administration. After protein extraction, $p$-JNK levels were measured by western blotting, which showed that APAP induced the expression of $p$-JNK; however, a suppressive effect was not observed in the Mito-T administered group (Figure 2C).

It was reported that the endoplasmic reticulum (ER) stress-inducible transcription factor CHOP induced cell death and was an important factor in the pathogenesis of different disease mouse models [19,38-42]. To investigate the effect of Mito-T on the expression of CHOP after APAP-induced liver injury, Mito-T (20 mg/kg, i.p.) was injected $1 \mathrm{~h}$ after APAP (400 mg/kg, i.p.) administration to C57BL/6J mice and tissue samples were collected $4 \mathrm{~h}$ after APAP injection. CHOP expression was measured by reverse transcription-polymerase chain reaction (RT-PCR) and immunostaining. The increased expression of Chop mRNA was observed after APAP treatment and a similar trend of increased Chop mRNA was found in the Mito-T group (Figure 2D). Furthermore, a similar increased expression pattern of CHOP positive cells was obtained for both groups (APAP and APAP + Mito-T) in CHOP immunostained mouse hepatic sections (Figure 2E,F). In addition, we observed that pretreatment with a JNK inhibitor, SP600125, significantly attenuated APAP-induced serum ALT levels confirming the involvement of JNK in the pathophysiology of our model (Figure S2).

Different types of mitochondrial ROS play a vital role in disease progression during APAP liver injury, where superoxide anions are the main reactive species converted to peroxynitrite by reacting with nitric oxide. Nitrotyrosine formation is a key mediator of peroxynitrite generation [43]. To confirm the effect of Mito-T on the APAP-induced hyper production of peroxynitrite in mitochondria, nitrotyrosine immunostaining was performed using an anti-nitrotyrosine antibody. An area stained with anti-nitrotyrosine antibody was observed in the APAP group but not in the APAP + Mito-T group (Figure 2G). Mitochondrial DNA fragmentation by DNA degrading enzymes during mitochondrial dysfunction was evaluated by the TUNEL staining assay. TUNEL positive cells were predominantly observed in liver sections of the APAP group, but very few were observed in the Mito-T treated group (Figure $2 \mathrm{H}$ ). We also measured ROS generation in isolated mitochondria from mouse groups using MitoSOX and CM- $\mathrm{H}_{2}$ DCFDA ROS detection probes. As shown in Supplemental Figure S3A,B, a significant increase in fluorescence intensity of the probes was observed in the APAP treated group compared with the vehicle group. Treatment with Mito-SOX significantly reduced this increase in fluorescence intensity. 
(A)

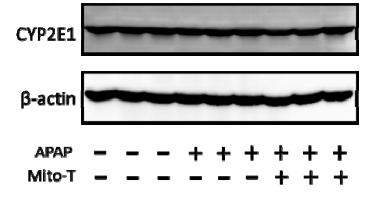

(D)

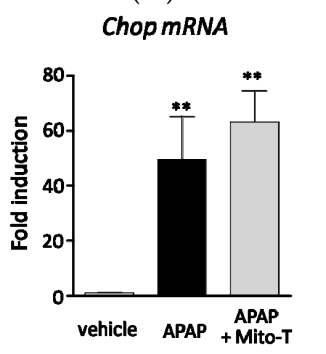

(B)

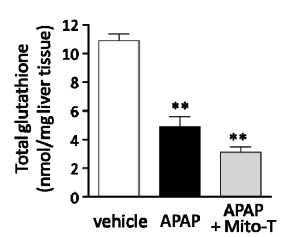

(C)
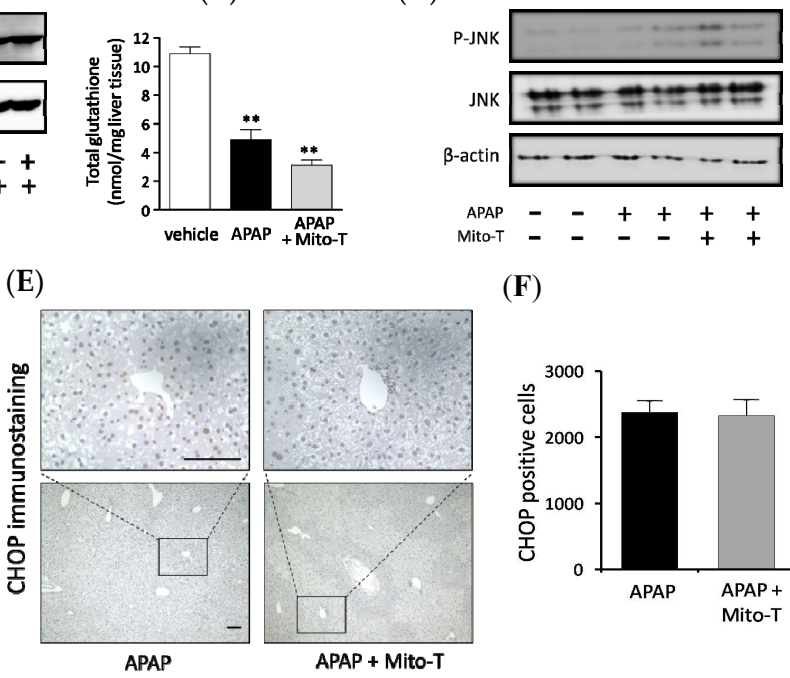

(F)

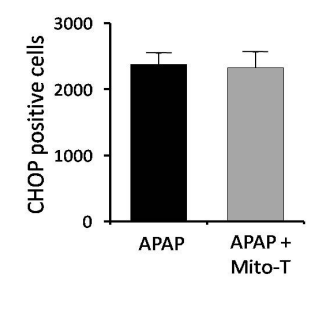

(G)

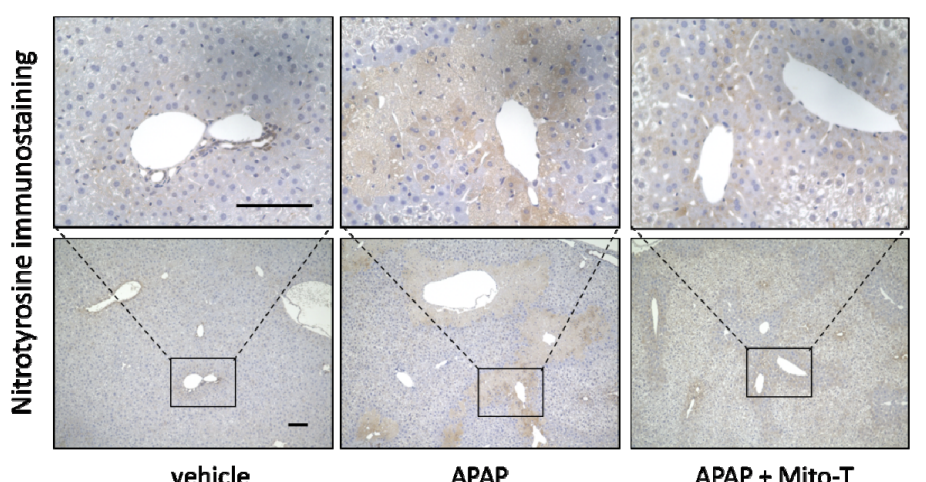

(H)

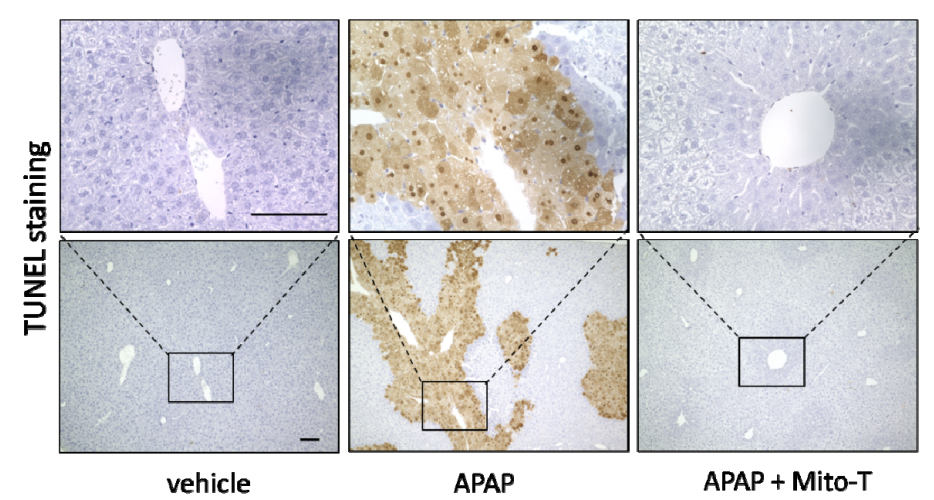

Figure 2. Effect of Mito-T on APAP liver injury pathophysiology. Mice were treated with APAP (400 mg/kg, i.p.) and $1 \mathrm{~h}$ later Mito-T (20 mg/kg, i.p.) or saline was administered. Liver tissue samples were collected from mice $4 \mathrm{~h}$ after APAP injection. Representative western blot of CYP2E1 expression (A) and total glutathione (GSH) level (B) in mouse liver is shown for each group. Each bar represents the mean \pm SEM $(n=3-4) .{ }^{* *} p<0.01$ vs. the saline group. (C) Representative western blot of $p$-c-jun $\mathrm{N}$-terminal kinases (JNK) and JNK expression in mouse livers $4 \mathrm{~h}$ after APAP administration. (D) Liver tissue samples were collected from mice $4 \mathrm{~h}$ after APAP injection. mRNA levels of Chopin mouse livers were analyzed by quantitative real-time RT-PCR. (E) Representative CHOP staining of mouse livers is shown. (F) CHOP positive cells were quantified from CHOP immunostained mouse livers. Each value represents the mean $\pm \operatorname{SEM}(n=3-4)$. ${ }^{* *} p<0.01$ vs. the saline group. (G) The liver samples were collected $8 \mathrm{~h}$ after APAP administration and nitrotyrosine immunohistochemical staining was performed. (H) The liver samples were collected $8 \mathrm{~h}$ after APAP administration and terminal deoxynucleotidyl transferase-mediated dUTP nick end labeling (TUNEL) immunohistochemical staining was performed. 


\subsection{Mito-T Prevents Cellular Injury and Reduces Mitochondrial Oxidative Stress in APAP-Treated HepG2 Cells}

We confirmed the hepatocellular protection against APAP hepatotoxicity by Mito-T in vitro. A significant decrease in cell viability was observed by $15 \mathrm{mM}$ APAP exposure compared with vehicle treatment. Mito-T $(10 \mu \mathrm{M})$ significantly alleviated the APAP-treated cytotoxicity in the 3D-NCP HepG2 cell culture (Figure 3A). The preventive effect of Mito-T was similar or greater than that of NAC $(100 \mu \mathrm{M})$.

(A)

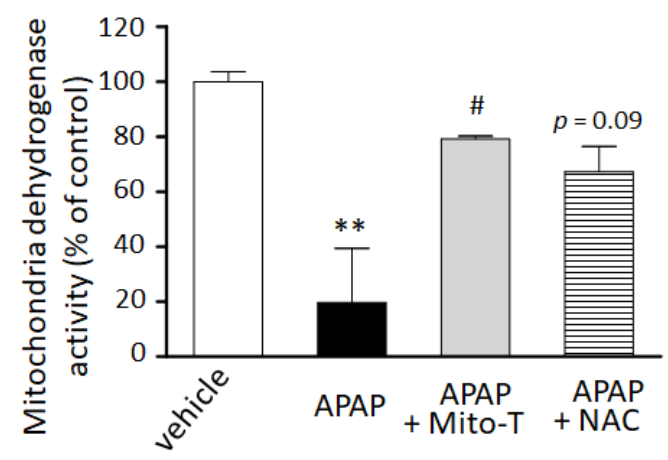

(B)

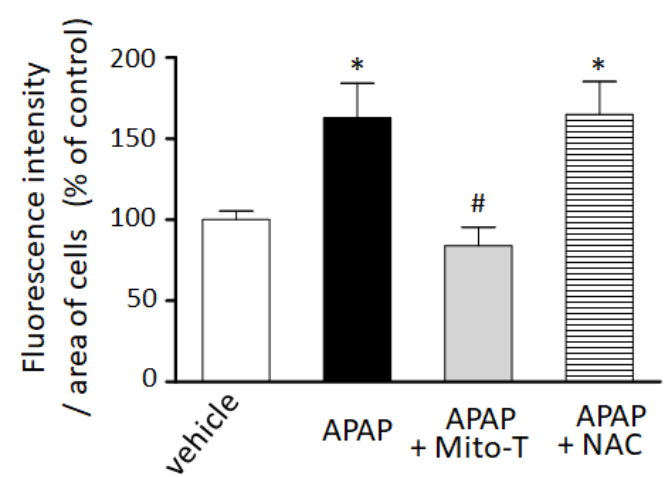

Figure 3. Preventive effect of Mito T and NAC against APAP-induced cellular injury and mitochondrial oxidative stress in a 3D cultured HepG2 cell model. HepG2 cells cultured in NCP (3D-NCP HepG2 cells) were exposed to $15 \mathrm{mM}$ APAP in the presence or absence of Mito-T (10 $\mu \mathrm{M})$ or NAC $(100 \mu \mathrm{M})$. The reagents were added just after cell exposure to APAP. (A) Cell viability was measured $24 \mathrm{~h}$ after APAP exposure by changes in mitochondrial dehydrogenase activity using the WST-8 assay kit. Each bar represents the mean $\pm \operatorname{SEM}(n=3)$. (B) MitoSOX $(5 \mu \mathrm{M})$ was added for $15 \mathrm{~min}$ after $24 \mathrm{~h}$ exposure to APAP. The cells were imaged at excitation/emission wavelengths of 490/510 nm and under bright field using a microscope. Random fields from each well were analyzed by microscopy, and the fluorescence of MitoSOX was quantified using ImageJ software $(1.47 \mathrm{v})$. Control or vehicle groups were treated with DMEM medium only. Each bar represents the mean $\pm \operatorname{SEM}(n=5) .{ }^{*} p<0.05,{ }^{* *} p<0.01$ vs. the vehicle group, \# $p<0.05$ vs. the APAP group.

We also examined the efficacy of Mito-T on mitochondrial oxidative stress reduction in the 3D NCP HepG2 cell culture system. As shown in Figure 3B, treatment with Mito-T (10 $\mu \mathrm{M})$ significantly reduced APAP $(15 \mathrm{mM})$-induced mitochondrial oxidative stress by MitoSOX whereas NAC $(100 \mu \mathrm{M})$ co-treatment did not attenuate the increased oxidative stress induced by APAP.

\subsection{Therapeutic Time Window of Mito-T and Its Role in APAP-Induced Liver Injury}

$\mathrm{N}$-acetyl L-cysteine (NAC) is the only clinically approved therapeutic for APAP-induced liver injury. It was reported that NAC acts upstream of the pathogenesis process. Previously it was shown that NAC is effective for early presenting patients; however, most cases of APAP-induced liver injury are hospitalized after several hours [44]. This study confirmed that Mito-T effectively decreased the transaminase level after APAP hepatotoxicity and that it functioned downstream of injury progression compared with NAC. We investigated the therapeutic time window of Mito-T and NAC in the APAP-induced liver injury model and found that Mito-T treatment was effective and might therefore be a candidate treatment. It was observed that at 1, 2, and $3 \mathrm{~h}$ after APAP $(400 \mathrm{mg} / \mathrm{kg}$, i.p.) administration, Mito-T ( $20 \mathrm{mg} / \mathrm{kg}$, i.p.) treatment significantly reduced the serum ALT level measured $24 \mathrm{~h}$ after APAP injection, whereas NAC $(600 \mathrm{mg} / \mathrm{kg}$, i.p.) administration only had a significant hepatoprotective effect at 1 and $2 \mathrm{~h}$ after APAP injection (Figure 4A). Representative H\&E staining (Figure 4B) showed Mito-T and NAC had similar effects on APAP-induced liver necrosis. 
(A)

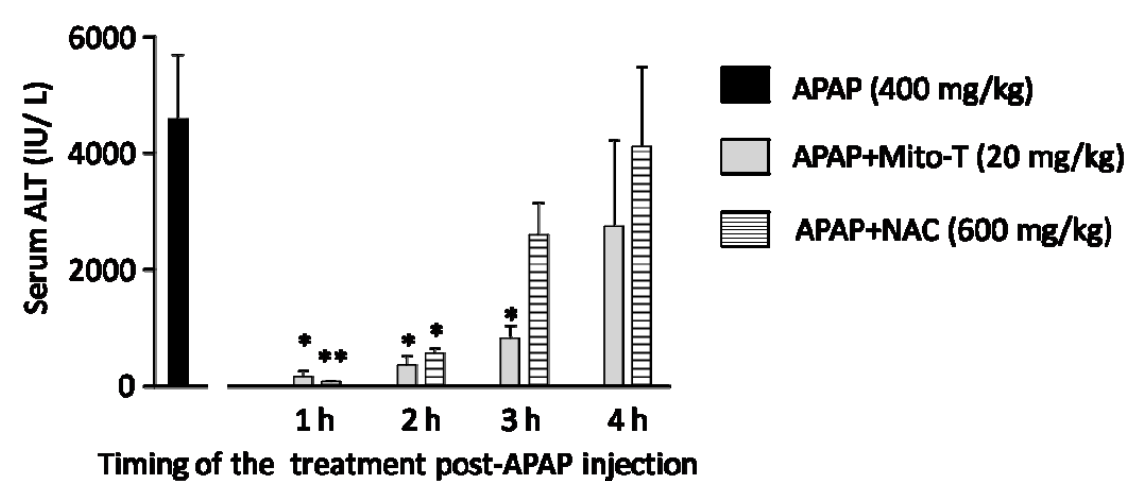

(B)
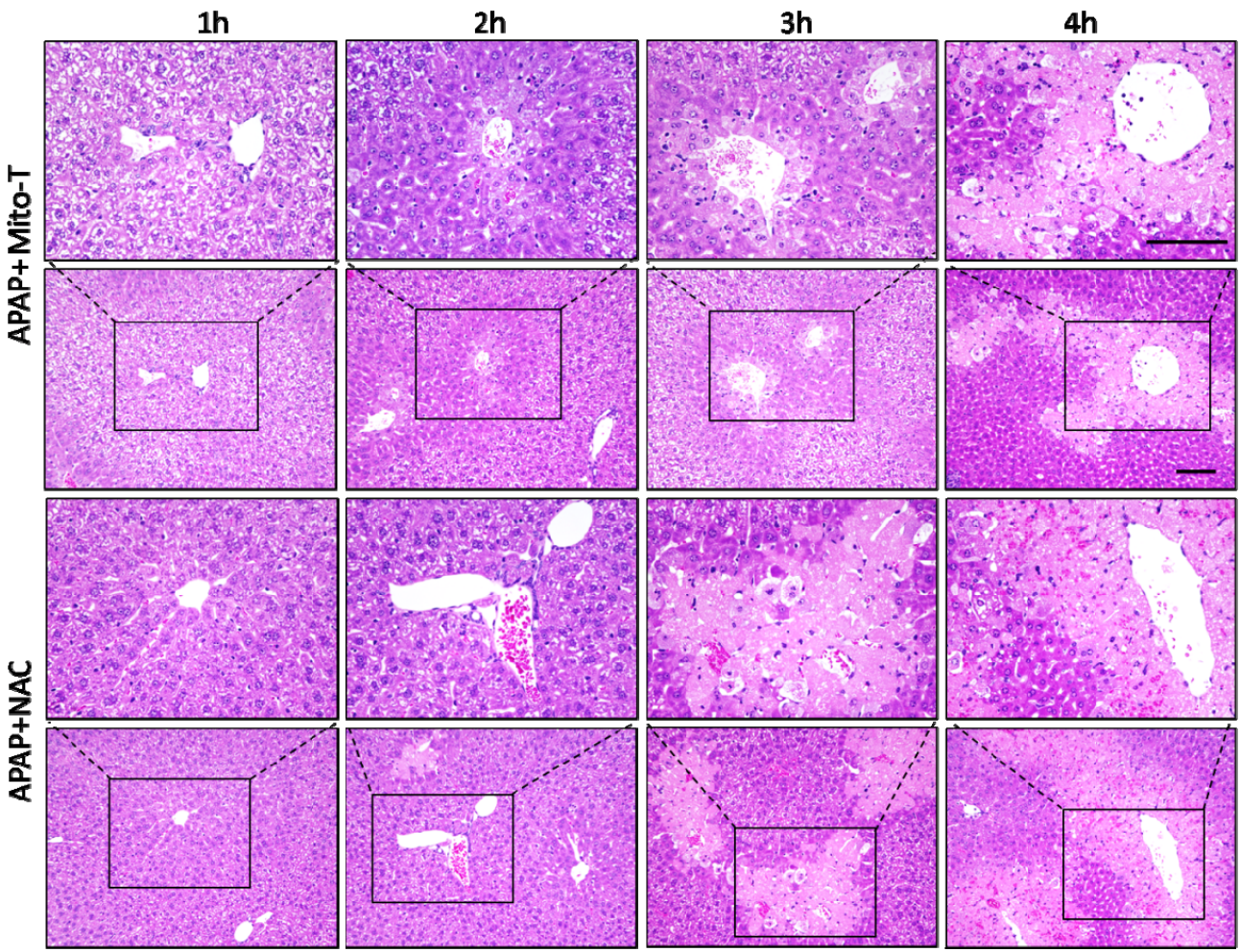

Figure 4. Therapeutic time window of Mito-T and NAC. Mito-T (20 mg/kg, i.p.) or NAC (600 mg/kg, i.p.) were administered at 1, 2, 3, and $4 \mathrm{~h}$ after APAP administration. Blood and liver tissue samples were collected $24 \mathrm{~h}$ after APAP $(400 \mathrm{mg} / \mathrm{kg}$, i.p.) injection. (A) Serum ALT activity was measured $24 \mathrm{~h}$ after APAP administration. (B) Representative hepatic sections from APAP+Mito-T and APAP+NAC groups were stained with H\&E. Scale bar: $100 \mu \mathrm{m}$. Each value represents the mean \pm SEM of 5-8 mice. ${ }^{*} p<0.05,{ }^{* *} p<0.01$ vs. the APAP group.

\subsection{Effect of Mito-T on Liver Regeneration after APAP-Induced Liver Injury}

After APAP-induced liver injury, damaged hepatocytes are removed by autophagy and homeostasis is maintained by the division and proliferation of healthy cells [45]. Proliferating cell nuclear antigen (PCNA) is a protein identified in cells at the late G1 phase to the early DNA synthesis phase ( $\mathrm{S}$ phase) after the division phase ( $\mathrm{M}$ phase) and is used as a cell cycle marker [46]. In this study, Mito-T ( $20 \mathrm{mg} / \mathrm{kg}$, i.p.) was administered $12 \mathrm{~h}$ after APAP ( $400 \mathrm{mg} / \mathrm{kg}$, i.p.) administration, the liver was excised $24 \mathrm{~h}$ later, and PCNA immunostaining was performed. The APAP and APAP+Mito-T groups had similar levels of PCNA positive cells (Figure 5). 

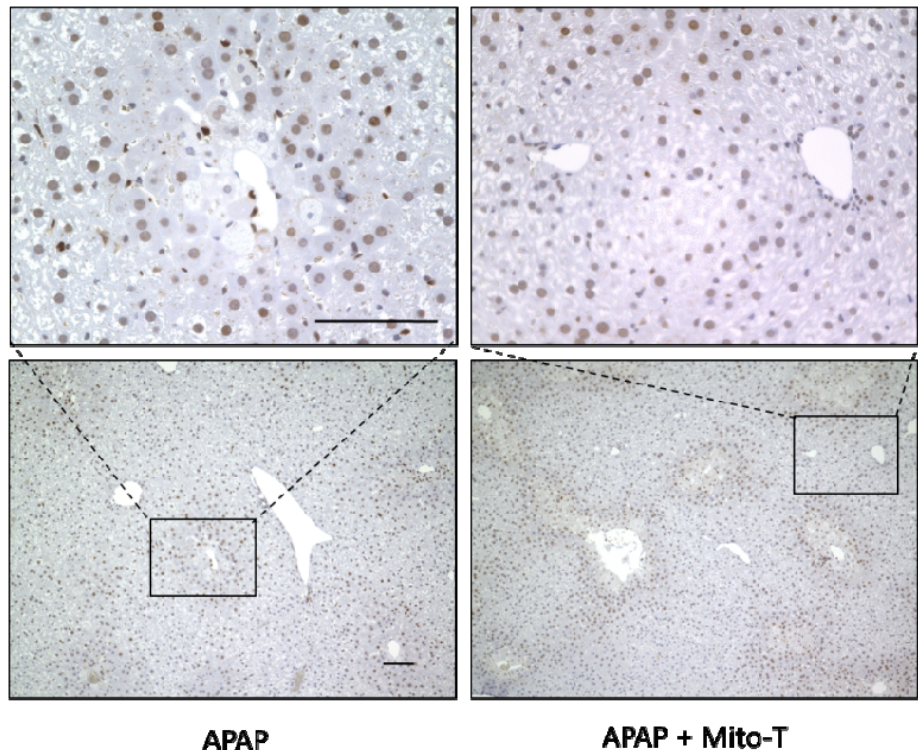

Figure 5. Effect of Mito-T on proliferating cell nuclear antigen (PCNA) expression. Mice were treated with Mito-T (20 mg/kg, i.p.) or saline $12 \mathrm{~h}$ after APAP (400 mg/kg, i.p.) administration. Liver tissue samples were collected $24 \mathrm{~h}$ after APAP injection. Representative PCNA staining of the hepatic sections in mice. Scale bar: $100 \mu \mathrm{m}$.

\subsection{Effect of Mito-T on Other Drug-Induced Liver Injury Models}

Because Mito-T had hepatoprotective effects against APAP-induced liver injury, we investigated whether Mito-T had a protective effect against other fulminate hepatic injury models similar to APAP liver injury. Carbon tetrachloride $\left(\mathrm{CCl}_{4}\right)$ is metabolized by CYP2E1 as is APAP and induces liver fibrosis by producing radicals [47]. In our study, Mito-T $(20 \mathrm{mg} / \mathrm{kg}$, i.p.) was administered $1 \mathrm{~h}$ after $\mathrm{CCl}_{4}\left(0.025 \mathrm{~mL} / \mathrm{kg}\right.$, i.p.) administration and serum ALT values were measured $24 \mathrm{~h}$ after $\mathrm{CCl}_{4}$ administration. An increased serum ALT level was observed in the $\mathrm{CCl}_{4}$-treated group, which was not attenuated by Mito-T treatment (Figure 6A). Concanavalin A (ConA) also induces hepatotoxicity by activating immune cells such as CD4+ T cells and inducing the production of TNF- $\alpha$, IL-6, IL- $1 \beta$, and IFN- $\gamma[48,49]$. In this hepatopathy model, inflammatory responses induce hepatic injury related to the activation of JNK, which is also induced during APAP-induced hepatopathy. One hour after ConA $(12.5 \mathrm{mg} / \mathrm{kg}$, i.v.) administration, Mito-T (20 mg/kg, i.p.) was administered and serum ALT levels were measured $24 \mathrm{~h}$ after ConA injection. Serum ALT levels were not suppressed by Mito-T (Figure 6B).

(A)

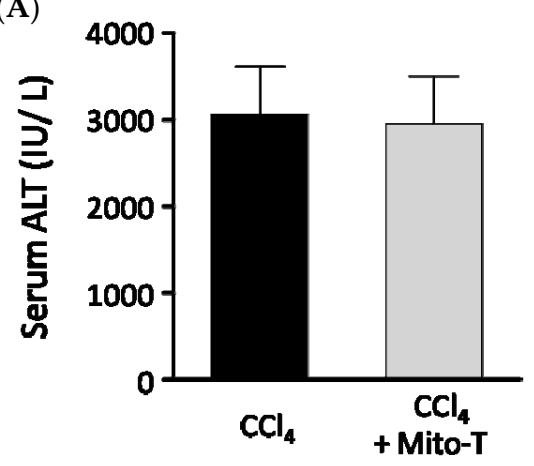

(B)

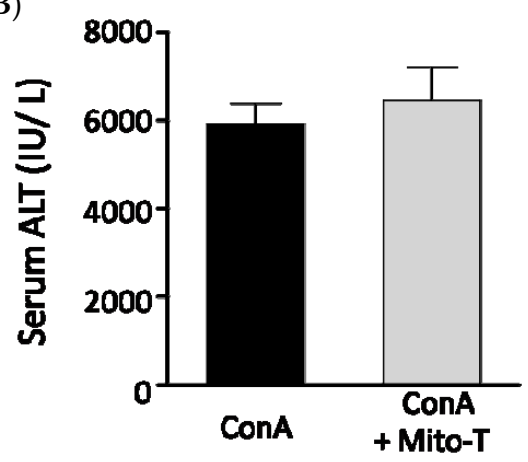

Figure 6. Effect of Mito-T on serum ALT levels in mice administered $\mathrm{CCl}_{4}$ or ConA. Mice were treated with Mito-T (20 mg/kg, i.p.) $1 \mathrm{~h}$ after $\mathrm{CCl}_{4}(0.025 \mathrm{mg} / \mathrm{kg}$, i.p.) or ConA (12.5 mg/kg, i.v.) administration. The serum ALT activity was measured $24 \mathrm{~h}$ after $\mathrm{CCl}_{4}(\mathrm{~A})$ or ConA (B) injection. Each value represents the mean \pm SEM $(n=6-8)$. 


\section{Discussion}

In this study, we confirmed the marked attenuation of APAP-induced serum ALT elevation and centrilobular necrosis in mice by Mito-T $(5-20 \mathrm{mg} / \mathrm{kg})$, which was dose- and time-dependent. We observed no effect on JNK and CHOP activation, CYP2E1 expression, and total GSH level. These data are similar to data reported by Du et al. [32,33]. We also demonstrated the attenuating potential of Mito-T in a human in vitro APAP 3D-HepG2 model [35]. In addition, we identified changes in PCNA expressions, and the therapeutic time-window in the mouse model. These data suggest that Mito-T is a potential therapeutic candidate to target mitochondrial oxidative stress.

JNK is a member of the mitogen-activated protein kinase (MAPK) family, which is activated by different stimuli, including drugs, ER stress, and ROS [50]. Following APAP administration, $p$-JNK translocates into mitochondria to induce opening of the mitochondrial permeability transition pore, which amplifies oxidative stress by mitochondrial ROS [15]. Although Mito-T has a significant protective effect, it does not attenuate $\mathrm{p}$-JNK protein expression. CHOP plays an important role in APAP liver injury progression [19], and we observed that Mito-T significantly attenuated APAP-induced liver injury and liver necroptosis without inhibiting the APAP-induced increase in ChopmRNA expression and liver CHOP immunostaining in the mouse model. Furthermore, we observed that SP600125 pretreatment significantly attenuated serum ALT elevation and Chop mRNA expression following APAP administration. Based on these findings, we suggest that the activation of JNK and CHOP are upstream of the APAP hepatotoxicity pathophysiology and that Mito-T might act downstream of this mechanistic pathway (Figure S4).

A human model for the study of APAP hepatotoxicity is urgently required because of the limitations of in vivo studies using murine models. In this study, we used an NCP-3D culture of HepG2 cells as an in vitro human model, which we previously reported shows the key mechanistic features of APAP hepatotoxicity and might be used to evaluate the mechanism and prospective drug candidates for APAP-induced hepatic injury [35]. Data from the current study indicate that Mito-T has cytoprotective potential for APAP-induced cell death in the 3D-HepG2 cell culture model (Figure 3) and that Mito-T significantly alleviated APAP-induced mitochondrial oxidative stress in the NCP 3D HepG2 cell culture system (Figure 4). Furthermore, it can be suggested that the attenuation of mitochondrial oxidative stress by Mito-T is independent of the contribution from inflammatory cells such as neutrophils and Kupffer cells.

NAC is the only current antidote for APAP-induced liver injury, and it is effective in early presenting APAP hepatotoxicity patients [51]. However, most APAP hepatotoxicity patients present $24 \mathrm{~h}$ or later [52]. In this study, the late-stage protective effect of Mito-T against APAP-induced liver injury was observed at $3 \mathrm{~h}$ after APAP treatment in the mouse model. A wide therapeutic time window of Mito-T might overcome the limitations of NAC treatment following APAP overdose-induced liver injury. This confirms the speculation of the superior efficacy of Mito-T over NAC [32,33]. It was reported that although early treatment with novel therapeutics alleviated APAP-induced liver injury, their late administration deteriorated liver injury and impaired liver regeneration $[53,54]$. Therapeutic approaches for acute liver injury following an overdose of APAP should consider the liver regeneration mechanistic pathway. Damaged hepatocytes undergo autophagy for clearance or proliferation for repair, which require oxidative stress. Therefore, the oxidative stress induced by APAP liver injury in the late phase plays a vital role in liver regeneration. PCNA was observed in cells at the late G1 phase to early DNA synthesis phase (S phase) after the division phase (M phase) [46]. In the current study, we demonstrated that late treatment (12 $\mathrm{h}$ after APAP administration) with Mito-T did not inhibit PCNA expression following APAP-induced liver injury.

APAP overdose induces liver injury and hepatic cell death occurs by oncotic necrosis, necroptosis [55,56] or apoptosis [57,58]. A recent report suggested that following necrosis, limited secondary apoptosis was induced by Mito-T after APAP overdose in a mouse model [33]. Liver histopathology indicated that Mito-T significantly attenuated APAP-induced hepatic DNA damage, although hepatic swelling and vacuolization were still present. The current study suggests 
that Mito-T attenuates APAP-induced liver injury and DNA fragmentation significantly, although some limitations remain regarding its protective effect. Therefore, further study is required to investigate the mechanism of APAP-induced hepatocyte death.

In this study, we demonstrated the attenuating effects of Mito-T against APAP hepatotoxicity in mouse and cellular models. However, this study had some limitations. First, the precise mechanism of the hepatoprotective action of Mito-T against APAP hepatotoxicity was not fully clarified. In this study, Mito-T prevented liver damage related to elevated serum ALT levels, nitrotyrosine formation, and DNA fragmentation, without any changes in p-JNK and CHOP expression. However, we did not evaluate other MAPK and ER stress-related mediators, such as extracellular signal-regulated kinase [59], p38 MAPK [60], X-box binding protein 1 [61], or inositol-requiring enzyme 1 $\alpha$ [61], which were reported to be important mediators in APAP hepatotoxicity. Further study is needed to investigate MAPK and ER stress-related mediators in the preventive mechanisms of Mito-T against APAP hepatotoxicity. Second, whether Mito-T can improve mitochondrial activity in hepatocytes during APAP hepatotoxicity is still unknown. Some reports demonstrated that APAP overdose reduced the activity of the electron transport chain during hepatotoxicity [27,62,63]. Although mitochondrial oxidative stress was evaluated using ROS detection probes and nitrotyrosine staining in mouse and cellular models in this study, we did not measure parameters that indicate mitochondrial activity, such as MitoTracker ${ }^{\mathrm{TM}}, \mathrm{CMXRos}$ fluorescence, isocitrate dehydrogenase-1 and 2, peroxisome proliferator-activated receptor $\gamma$ coactivator- $1 \alpha$ expression, or lactate dehydrogenase activity. We also examined mitochondria dehydrogenase activity using a WST-8 assay in the HepG2 cell system and found that Mito-T might attenuate the dysfunction of mitochondrial activity in APAP-exposed hepatocytes. However, further experiments are required to confirm this. Third, the effect of Mito-T on liver recovery from APAP intoxication, such as hepatocyte regeneration, and comparison of the effects with NAC were not fully identified. As mentioned above, we evaluated the effect of late-phase treatment with Mito-T during APAP liver injury using PCNA staining. However, other cell proliferation biomarkers, such as bromodeoxyuridine, cyclin D1, and Ki67, were not measured. In addition, we did not examine whether the normal tissue repair process occurred without abnormal healing such as remodeling, after Mito-T treatment. Indeed, Du et al. [33] suggested that Mito-T might limit secondary apoptosis, which may be important in the recovery process during late-phase liver injury. They also reported that an approved antidote NAC did not inhibit secondary apoptosis during the late phase of APAP hepatotoxicity. However, Yang et al. [64] reported that prolonged treatment with NAC significantly impaired liver regeneration during hepatotoxicity. Therefore, the effect of NAC on liver regeneration is controversial and further study to elucidate and compare the action of Mito-T and NAC in the repair process is warranted. Fourth, there is a critical difference in the cellular APAP liver injury model using 3D-cultured HepG2 cells and clinical APAP hepatotoxicity. For example, the concentration of APAP (15 mM) that induces significant cellular damage in 3D HepG2 cells was approximately $>5$ times higher than the blood levels of APAP in patients with APAP intoxication [65]. This difference is a common limitation in the cellular models of APAP hepatotoxicity, including primary cultured hepatocytes $[54,66]$ and HepaRG cells $[67,68]$. Despite these limitations, we previously demonstrated that the 3D HepG2 cell model was similar to APAP liver injury with regards to NAPQI production, GSH depletion, and JNK pathway activation, indicating it might be a useful model to screen drug candidates for APAP hepatotoxicity [35]. Furthermore, the results from cellular experiments suggested that Mito-T protected hepatocytes independent from the influence of immune cells such as Kupffer cells and neutrophils. Finally, the time course of APAP hepatotoxicity progression was distinct from that of clinical patients with APAP liver injury. Indeed, the progression of live injury after APAP overdose tends to be much faster in mice than in humans. Previous studies reported that the maximum serum ALT elevation and centrilobular necrosis were observed between 12 and $24 \mathrm{~h}$ in mice [69] and $36-48 \mathrm{~h}$ in humans after an overdose of APAP [44]. When considering the therapeutic time-window of Mito-T and NAC, we cannot ignore the "species-dependent effect" in mice. Although the mouse model is considered the most representative model of liver injury in APAP intoxication patients, 
further study is warranted to demonstrate the therapeutic time-window of Mito-T and NAC in other models, using human hepatocytes, such as primary culture cells or HepaRG cells. Nevertheless, this study reports the beneficial action of Mito-T in APAP hepatotoxicity models and the critical role of mitochondrial oxidative stress in the development of APAP hepatotoxicity.

\section{Conclusions}

The protective effect of Mito-T against APAP-induce liver injury was confirmed in this study using mouse and human models. Mito-T markedly attenuated the APAP increase in transaminase levels, mitochondrial oxidative stress, nitrotyrosine formation, hepatic DNA damage, and hepatic necroptosis. This study confirmed the specific protective mechanism of Mito-T following APAP hepatotoxicity and its effectiveness in liver regeneration. We suggest that Mito-T is a potential therapeutic candidate that targets mitochondrial oxidative stress and which can function in the late phase of APAP-liver injury when compared with NAC, although additional studies are necessary to confirm this.

Supplementary Materials: The following are available online at http://www.mdpi.com/2076-3921/9/10/965/s1, Figure S1. Quantification of CHOP positive cells in immunohistological images. Figure S2. CHOP induction in APAP liver injury and the effect of a JNK inhibitor. Figure S3. Mito-T reduces APAP-induced mitochondrial oxidative stress in mouse livers. Figure S4. Pathophysiology of APAP-induced liver injury.

Author Contributions: Conceptualization, Y.I.; project administration, Y.I.; methodology, Y.I., H.M., and T.M.; investigation, K.S., M.A.-A.-S., S.K., N.N., K.U., and H.M.; validation, M.A.-A.-S.; formal analysis, Y.I., K.S., and S.K.; Visualization M.A.-A.-S. and Y.I.; writing-original draft preparation, M.A.-A.-S. and Y.I.; writing-review and editing, Y.I., M.A.-A.-S., Y.K. and T.I.; supervision, Y.I., Y.K., H.M., T.M. and T.I.; funding acquisition, Y.I. and T.I. All authors have read and agreed to the published version of the manuscript.

Funding: This research was funded by the Japan Society for the Promotion of Science (JSPS KAKENHI grant numbers 21790524, 23790603, 26460629 and 17K08955) and supported in part by the Program for Leading Graduate Schools "HIGO (Health life science: Interdisciplinary and Glocal Oriented) Program", MEXT, Japan.

Acknowledgments: We thank J. Ludovic Croxford, from Edanz Group (https://en-author-services.edanzgroup. $\mathrm{com} / \mathrm{ac})$ for editing a draft of this manuscript.

Conflicts of Interest: The authors declare no conflict of interest.

\section{References}

1. Graham, G.G.; Scott, K.F.; Day, R.O. Tolerability of Paracetamol. Drug Saf. 2005, 28, 227-240. [CrossRef]

2. Nourjah, P.; Ahmad, S.R.; Karwoski, C.; Willy, M. Estimates of acetaminophen (paracetomal)-associated overdoses in the United States. Pharmacoepidemiol. Drug Saf. 2006, 15, 398-405. [CrossRef] [PubMed]

3. Michna, E.; Duh, M.S.; Korves, C.; Dahl, J.L. Removal of Opioid/Acetaminophen Combination Prescription Pain Medications: Assessing the Evidence for Hepatotoxicity and Consequences of Removal of These Medications. Pain Med. 2010, 11, 369-378. [CrossRef] [PubMed]

4. Lee, W.M. Acetaminophen (APAP) hepatotoxicity-Isn't it time for APAP to go away? J. Hepatol. 2017, 67, 1324-1331. [CrossRef] [PubMed]

5. Craig, D.G.N.; Bates, C.M.; Davidson, J.S.; Martin, K.G.; Hayes, P.C.; Simpson, K.J. Overdose pattern and outcome in paracetamol-induced acute severe hepatotoxicity. Br. J. Clin. Pharmacol. 2011, 71, 273-282. [CrossRef] [PubMed]

6. Li, C.; Martin, B.C. Trends in emergency department visits attributable to acetaminophen overdoses in the United States: 1993-2007. Pharmacoepidemiol. Drug Saf. 2011, 20, 810-818. [CrossRef] [PubMed]

7. Bernal, W.; Auzinger, G.; Dhawan, A.; Wendon, J. Acute liver failure. Lancet 2010, 376, 190-201. [CrossRef]

8. Lee, S.S.T.; Buters, J.T.M.; Pineau, T.; Fernandez-Salguero, P.; Gonzalez, F.J. Role of CYP2E1 in the Hepatotoxicity of Acetaminophen. J. Biol. Chem. 1996, 271, 12063-12067. [CrossRef] [PubMed]

9. Gonzalez, F.J. Role of cytochromes P450 in chemical toxicity and oxidative stress: Studies with CYP2E1. Mutat. Res. Mol. Mech. Mutagen. 2005, 569, 101-110. [CrossRef] [PubMed]

10. Cohen, S.D.; Pumford, N.R.; Khairallah, E.A.; Boekelheide, K.; Pohl, L.R.; Amouzadeh, H.R.; Hinson, J.A. Selective Protein Covalent Binding and Target Organ Toxicity. Toxicol. Appl. Pharmacol. 1997, 143, 1-12. [CrossRef]

11. McGill, M.R.; Jaeschke, H. Metabolism and Disposition of Acetaminophen: Recent Advances in Relation to Hepatotoxicity and Diagnosis. Pharm. Res. 2013, 30, 2174-2187. [CrossRef] [PubMed] 
12. Meyers, L.L.; Beierschmitt, W.P.; Khairallah, E.A.; Cohen, S.D. Acetaminophen-induced inhibition of hepatic mitochondrial respiration in mice. Toxicol. Appl. Pharmacol. 1988, 93, 378-387. [CrossRef]

13. Jaeschke, H. Glutathione disulfide formation and oxidant stress during acetaminophen-induced hepatotoxicity in mice in vivo: The protective effect of allopurinol. J. Pharmacol. Exp. Ther. 1990, 255, 935-941. [PubMed]

14. Donnelly, P.J.; Walker, R.M.; Racz, W.J. Inhibition of mitochondrial respiration in vivo is an early event in acetaminophen-induced hepatotoxicity. Arch. Toxicol. 1994, 68, 110. [CrossRef] [PubMed]

15. Hanawa, N.; Shinohara, M.; Saberi, B.; Gaarde, W.A.; Han, D.; Kaplowitz, N. Role of JNK Translocation to Mitochondria Leading to Inhibition of Mitochondria Bioenergetics in Acetaminophen-induced Liver Injury. J. Biol. Chem. 2008, 283, 13565-13577. [CrossRef]

16. Du, K.; Ramachandran, A.; Jaeschke, H. Oxidative stress during acetaminophen hepatotoxicity: Sources, pathophysiological role and therapeutic potential. Redox Biol. 2016, 10, 148-156. [CrossRef]

17. Hinson, J.A.; Pike, S.L.; Pumford, N.R.; Mayeux, P.R. Nitrotyrosine-Protein Adducts in Hepatic Centrilobular Areas following Toxic Doses of Acetaminophen in Mice. Chem. Res. Toxicol. 1998, 11, 604-607. [CrossRef]

18. LoGuidice, A.; Boelsterli, U.A. Acetaminophen overdose-induced liver injury in mice is mediated by peroxynitrite independently of the cyclophilin D-regulated permeability transition. Hepatology 2011, 54, 969-978. [CrossRef]

19. Uzi, D.; Barda, L.; Scaiewicz, V.; Mills, M.; Mueller, T.; Gonzalez-Rodriguez, A.; Valverde, A.M.; Iwawaki, T.; Nahmias, Y.; Xavier, R.; et al. CHOP is a critical regulator of acetaminophen-induced hepatotoxicity. J. Hepatol. 2013, 59, 495-503. [CrossRef]

20. Masubuchi, Y.; Sugiyama, S.; Horie, T. Th1/Th2 cytokine balance as a determinant of acetaminophen-induced liver injury. Chem. Biol. Interact. 2009, 179, 273-279. [CrossRef]

21. James, L.P.; McCullough, S.S.; Lamps, L.W.; Hinson, J.A. Effect of N-Acetylcysteine on Acetaminophen Toxicity in Mice: Relationship to Reactive Nitrogen and Cytokine Formation. Toxicol. Sci. 2003, 75, 458-467. [CrossRef] [PubMed]

22. Jaeschke, H.; Williams, C.D.; Ramachandran, A.; Bajt, M.L. Acetaminophen hepatotoxicity and repair: The role of sterile inflammation and innate immunity. Liver Int. Off. J. Int. Assoc. Study Liver 2012, 32, 8-20. [CrossRef] [PubMed]

23. Friedman, J.R.; Nunnari, J. Mitochondrial form and function. Nature 2014, 505, 335-343. [CrossRef] [PubMed]

24. Russo, E.; Nguyen, H.; Lippert, T.; Tuazon, J.; Borlongan, C.V.; Napoli, E. Mitochondrial targeting as a novel therapy for stroke. Brain Circ. 2018, 4, 84-94. [CrossRef]

25. Teixeira, J.; Deus, C.M.; Borges, F.; Oliveira, P.J. Mitochondria: Targeting mitochondrial reactive oxygen species with mitochondriotropic polyphenolic-based antioxidants. Int. J. Biochem. Cell Biol. 2018, 97, 98-103. [CrossRef]

26. Murphy, M.P.; Hartley, R.C. Mitochondria as a therapeutic target for common pathologies. Nat. Rev. Drug Discov. 2018, 17, 865-886. [CrossRef]

27. McGill, M.R.; Sharpe, M.R.; Williams, C.D.; Taha, M.; Curry, S.C.; Jaeschke, H. The mechanism underlying acetaminophen-induced hepatotoxicity in humans and mice involves mitochondrial damage and nuclear DNA fragmentation. J. Clin. Investig. 2012, 122, 1574-1583. [CrossRef]

28. Du, K.; Ramachandran, A.; Weemhoff, J.L.; Chavan, H.; Xie, Y.; Krishnamurthy, P.; Jaeschke, H. Editor's Highlight: Metformin Protects Against Acetaminophen Hepatotoxicity by Attenuation of Mitochondrial Oxidant Stress and Dysfunction. Toxicol. Sci. 2016, 154, 214-226. [CrossRef]

29. Lee, K.K.; Imaizumi, N.; Chamberland, S.R.; Alder, N.N.; Boelsterli, U.A. Targeting mitochondria with methylene blue protects mice against acetaminophen-induced liver injury. Hepatology 2015, 61, 326-336. [CrossRef]

30. Shi, X.; Bai, H.; Zhao, M.; Li, X.; Sun, X.; Jiang, H.; Fu, A. Treatment of acetaminophen-induced liver injury with exogenous mitochondria in mice. Transl. Res. 2018, 196, 31-41. [CrossRef]

31. Trnka, J.; Blaikie, F.H.; Smith, R.A.J.; Murphy, M.P. A mitochondria-targeted nitroxide is reduced to its hydroxylamine by ubiquinol in mitochondria. Free Radic. Biol. Med. 2008, 44, 1406-1419. [CrossRef]

32. Du, K.; Farhood, A.; Jaeschke, H. Mitochondria-targeted antioxidant Mito-Tempo protects against acetaminophen hepatotoxicity. Arch. Toxicol. 2017, 91,761-773. [CrossRef] [PubMed]

33. Du, K.; Ramachandran, A.; Weemhoff, J.L.; Woolbright, B.L.; Jaeschke, A.H.; Chao, X.; Ding, W.-X.; Jaeschke, H. Mito-tempo protects against acute liver injury but induces limited secondary apoptosis during the late phase of acetaminophen hepatotoxicity. Arch. Toxicol. 2019, 93, 163-178. [CrossRef] [PubMed] 
34. Shimizu, D.; Ishitsuka, Y.; Miyata, K.; Tomishima, Y.; Kondo, Y.; Irikura, M.; Iwawaki, T.; Oike, Y.; Irie, T. Protection afforded by pre- or post-treatment with 4-phenylbutyrate against liver injury induced by acetaminophen overdose in mice. Pharmacol. Res. 2014, 87, 26-41. [CrossRef]

35. Aritomi, K.; Ishitsuka, Y.; Tomishima, Y.; Shimizu, D.; Abe, N.; Shuto, T.; Irikura, M.; Kai, H.; Irie, T. Evaluation of three-dimensional cultured HepG2 cells in a nano culture plate system: An in vitro human model of acetaminophen hepatotoxicity. J. Pharmacol. Sci. 2014, 124, 218-229. [CrossRef]

36. Umezaki, Y.; Iohara, D.; Anraku, M.; Ishitsuka, Y.; Irie, T.; Uekama, K.; Hirayama, F. Preparation of hydrophilic $\mathrm{C} 60(\mathrm{OH}) 10 / 2$-hydroxypropyl- $\beta$-cyclodextrin nanoparticles for the treatment of a liver injury induced by an overdose of acetaminophen. Biomaterials 2015, 45, 115-123. [CrossRef]

37. Tomishima, Y.; Ishitsuka, Y.; Matsunaga, N.; Nagatome, M.; Furusho, H.; Irikura, M.; Ohdo, S.; Irie, T. Ozagrel hydrochloride, a selective thromboxane A2 synthase inhibitor, alleviates liver injury induced by acetaminophen overdose in mice. BMC Gastroenterol. 2013, 13, 21. [CrossRef] [PubMed]

38. Tanaka, Y.; Ishitsuka, Y.; Hayasaka, M.; Yamada, Y.; Miyata, K.; Endo, M.; Kondo, Y.; Moriuchi, H.; Irikura, M.; Tanaka, K.; et al. The exacerbating roles of CCAAT/enhancer-binding protein homologous protein (CHOP) in the development of bleomycin-induced pulmonary fibrosis and the preventive effects of tauroursodeoxycholic acid (TUDCA) against pulmonary fibrosis in mice. Pharmacol. Res. 2015, 99, 52-62. [CrossRef] [PubMed]

39. Chen, Q.; Yan, D.; Zhang, Q.; Zhang, G.; Xia, M.; Li, J.; Zhan, W.; Shen, E.; Li, Z.; Lin, L.; et al. Treatment of acetaminophen-induced liver failure by blocking the death checkpoint protein TRAIL. Biochim. Biophys. Acta BBA Mol. Basis Dis. 2020, 1866, 165583. [CrossRef] [PubMed]

40. Endo, M.; Mori, M.; Akira, S.; Gotoh, T. C/EBP Homologous Protein (CHOP) Is Crucial for the Induction of Caspase-11 and the Pathogenesis of Lipopolysaccharide-Induced Inflammatio. J. Immunol. 2006, 176, 6245-6253. [CrossRef] [PubMed]

41. Kong, F.-J.; Ma, L.-L.; Guo, J.-J.; Xu, L.-H.; Li, Y.; Qu, S. Endoplasmic reticulum stress/autophagy pathway is involved in diabetes-induced neuronal apoptosis and cognitive decline in mice. Clin. Sci. 2018, 132, 111-125. [CrossRef] [PubMed]

42. Liu, W.; Liu, K.; Zhang, S.; Shan, L.; Tang, J. Tetramethylpyrazine Showed Therapeutic Effects on Sepsis-Induced Acute Lung Injury in Rats by Inhibiting Endoplasmic Reticulum Stress Protein Kinase RNA-Like Endoplasmic Reticulum Kinase (PERK) Signaling-Induced Apoptosis of Pulmonary Microvascular Endothelial Cells. Med. Sci. Monit. Int. Med. J. Exp. Clin. Res. 2018, 24, 1225-1231. [CrossRef]

43. Agarwal, R.; Hennings, L.; Rafferty, T.M.; Letzig, L.G.; McCullough, S.; James, L.P.; MacMillan-Crow, L.A.; Hinson, J.A. Acetaminophen-Induced Hepatotoxicity and Protein Nitration in Neuronal Nitric-Oxide Synthase Knockout Mice. J. Pharmacol. Exp. Ther. 2012, 340, 134-142. [CrossRef]

44. Larson, A.M. Acetaminophen hepatotoxicity. Clin. Liver Dis. 2007, 11, 525-548. [CrossRef] [PubMed]

45. Gao, Y.; Chu, S.; Zhang, Z.; Zuo, W.; Xia, C.; Ai, Q.; Luo, P.; Cao, P.; Chen, N. Early Stage Functions of Mitochondrial Autophagy and Oxidative Stress in Acetaminophen-Induced Liver Injury. J. Cell. Biochem. 2017, 118, 3130-3141. [CrossRef]

46. Albrecht, J.H.; Poon, R.Y.; Ahonen, C.L.; Rieland, B.M.; Deng, C.; Crary, G.S. Involvement of p21 and p27 in the regulation of CDK activity and cell cycle progression in the regenerating liver. Oncogene 1998, 16, 2141-2150. [CrossRef]

47. Slater, T.F.; Cheeseman, K.H.; Ingold, K.U. Carbon tetrachloride toxicity as a model for studying free-radical mediated liver injury. Philos. Trans. R. Soc. Lond. B Biol. Sci. 1985, 311. [CrossRef]

48. Tiegs, G.; Hentschel, J.; Wendel, A. A T cell-dependent experimental liver injury in mice inducible by concanavalin A. J. Clin. Investig. 1992, 90, 196-203. [CrossRef]

49. Itoh, A.; Isoda, K.; Kondoh, M.; Kawase, M.; Kobayashi, M.; Tamesada, M.; Yagi, K. Hepatoprotective Effect of Syringic Acid and Vanillic Acid on Concanavalin A-Induced Liver Injury. Biol. Pharm. Bull. 2009, 32, 1215-1219. [CrossRef]

50. Seki, E.; Brenner, D.A.; Karin, M. A Liver Full of JNK: Signaling in Regulation of Cell Function and Disease Pathogenesis, and Clinical Approaches. Gastroenterology 2012, 143, 307-320. [CrossRef]

51. Rumack, B.H.; Peterson, R.C.; Koch, G.G.; Amara, I.A. Acetaminophen Overdose: 662 Cases With Evaluation of Oral Acetylcysteine Treatment. JAMA Intern. Med. 1981, 141, 380-385. [CrossRef]

52. Craig, D.G.N.; Bates, C.M.; Davidson, J.S.; Martin, K.G.; Hayes, P.C.; Simpson, K.J. Staggered overdose pattern and delay to hospital presentation are associated with adverse outcomes following paracetamol-induced hepatotoxicity. Br. J. Clin. Pharmacol. 2012, 73, 285-294. [CrossRef] [PubMed] 
53. Yang, R.; Zou, X.; Koskinen, M.-L.; Tenhunen, J. Ethyl pyruvate reduces liver injury at early phase but impairs regeneration at late phase in acetaminophen overdose. Crit. Care 2012, 16, R9. [CrossRef] [PubMed]

54. Bhushan, B.; Chavan, H.; Borude, P.; Xie, Y.; Du, K.; McGill, M.R.; Lebofsky, M.; Jaeschke, H.; Krishnamurthy, P.; Apte, U. Dual Role of Epidermal Growth Factor Receptor in Liver Injury and Regeneration after Acetaminophen Overdose in Mice. Toxicol. Sci. 2016, 155, 363-378. [CrossRef]

55. Gujral, J.S.; Knight, T.R.; Farhood, A.; Bajt, M.L.; Jaeschke, H. Mode of Cell Death after Acetaminophen Overdose in Mice: Apoptosis or Oncotic Necrosis? Toxicol. Sci. 2002, 67, 322-328. [CrossRef]

56. Jaeschke, H.; Williams, C.D.; Farhood, A. No evidence for caspase-dependent apoptosis in acetaminophen hepatotoxicity. Hepatol. Baltim. Md. 2011, 53, 718-719. [CrossRef]

57. Chen, Y.; Park, H.-J.; Park, J.; Song, H.-C.; Ryter, S.W.; Surh, Y.-J.; Kim, U.-H.; Joe, Y.; Chung, H.T. Carbon monoxide ameliorates acetaminophen-induced liver injury by increasing hepatic HO-1 and Parkin expression. FASEB J. 2019, 33, 13905-13919. [CrossRef]

58. Shi, C.; Hao, B.; Yang, Y.; Muhammad, I.; Zhang, Y.; Chang, Y.; Li, Y.; Li, C.; Li, R.; Liu, F. JNK Signaling Pathway Mediates Acetaminophen-Induced Hepatotoxicity Accompanied by Changes of Glutathione S-Transferase A1 Content and Expression. Front. Pharmacol. 2019, 10, 1092. [CrossRef]

59. Liu, F.-C.; Lee, H.-C.; Liao, C.-C.; Li, A.H.; Yu, H.-P. Tropisetron Protects Against Acetaminophen-Induced Liver Injury via Suppressing Hepatic Oxidative Stress and Modulating the Activation of JNK/ERK MAPK Pathways. Available online: https://www.hindawi.com/journals/bmri/2016/1952947/ (accessed on 3 September 2020).

60. Mobasher, M.A.; González-Rodriguez, Á.; Santamaría, B.; Ramos, S.; Martín, M.Á.; Goya, L.; Rada, P.; Letzig, L.; James, L.P.; Cuadrado, A.; et al. Protein tyrosine phosphatase 1B modulates GSK3 $\beta$ /Nrf2 and IGFIR signaling pathways in acetaminophen-induced hepatotoxicity. Cell Death Dis. 2013, 4, e626. [CrossRef]

61. Hur, K.Y.; So, J.-S.; Ruda, V.; Frank-Kamenetsky, M.; Fitzgerald, K.; Koteliansky, V.; Iwawaki, T.; Glimcher, L.H.; Lee, A.-H. IRE1 $\alpha$ activation protects mice against acetaminophen-induced hepatotoxicity. J. Exp. Med. 2012, 209, 307-318. [CrossRef]

62. Jiang, J.; Briedé, J.J.; Jennen, D.G.J.; Van Summeren, A.; Saritas-Brauers, K.; Schaart, G.; Kleinjans, J.C.S.; de Kok, T.M.C.M. Increased mitochondrial ROS formation by acetaminophen in human hepatic cells is associated with gene expression changes suggesting disruption of the mitochondrial electron transport chain. Toxicol. Lett. 2015, 234, 139-150. [CrossRef] [PubMed]

63. Jaeschke, H.; McGill, M.R.; Ramachandran, A. Oxidant stress, mitochondria, and cell death mechanisms in drug-induced liver injury: Lessons learned from acetaminophen hepatotoxicity. Drug Metab. Rev. 2012, 44, 88-106. [CrossRef]

64. Yang, R.; Miki, K.; He, X.; Killeen, M.E.; Fink, M.P. Prolonged treatment with N-acetylcystine delays liver recovery from acetaminophen hepatotoxicity. Crit. Care 2009, 13, R55. [CrossRef]

65. Muldrew, K.L.; James, L.P.; Coop, L.; McCullough, S.S.; Hendrickson, H.P.; Hinson, J.A.; Mayeux, P.R. Determination of Acetaminophen-Protein Adducts in Mouse Liver and Serum and Human Serum after Hepatotoxic Doses of Acetaminophen Using High-Performance Liquid Chromatography with Electrochemical Detection. Drug Metab. Dispos. 2002, 30, 446-451. [CrossRef] [PubMed]

66. Xie, Y.; McGill, M.R.; Dorko, K.; Kumer, S.C.; Schmitt, T.M.; Forster, J.; Jaeschke, H. Mechanisms of acetaminophen-induced cell death in primary human hepatocytes. Toxicol. Appl. Pharmacol. 2014, 279, 266-274. [CrossRef] [PubMed]

67. McGill, M.R.; Yan, H.-M.; Ramachandran, A.; Murray, G.J.; Rollins, D.E.; Jaeschke, H. HepaRG cells: A human model to study mechanisms of acetaminophen hepatotoxicity. Hepatology 2011, 53, 974-982. [CrossRef]

68. Choi, Y.-H.; Lee, H.S.; Chung, C.-K.; Kim, E.J.; Kang, I.-J. Protective effects of an ethanol extract of Angelica keiskei against acetaminophen-induced hepatotoxicity in HepG2 and HepaRG cells. Nutr. Res. Pract. 2017, 11, 97-104. [CrossRef] [PubMed]

69. McGill, M.R.; Lebofsky, M.; Norris, H.-R.K.; Slawson, M.H.; Bajt, M.L.; Xie, Y.; Williams, C.D.; Wilkins, D.G.; Rollins, D.E.; Jaeschke, H. Plasma and liver acetaminophen-protein adduct levels in mice after acetaminophen treatment: Dose-response, mechanisms, and clinical implications. Toxicol. Appl. Pharmacol. 2013, 269, 240-249. [CrossRef]

(C) 2020 by the authors. Licensee MDPI, Basel, Switzerland. This article is an open access article distributed under the terms and conditions of the Creative Commons Attribution (CC BY) license (http://creativecommons.org/licenses/by/4.0/). 